\title{
Apontamentos sobre a contribuição da sociologia das formas de Franco Moretti para os estudos em jornalismo ${ }^{1}$
}

\author{
Notes about the contribution of Franco \\ Moretti's sociology of forms to journalism \\ studies
}

\author{
- MARCOS PA UlO DA Silva a \\ Universidade Federal de Mato Grosso do Sul, Mestrado em Comunicação. Campo Grande - MS, Brasil
}

\section{RESUMO}

O artigo apresenta apontamentos sobre a contribuição teórico-metodológica da proposta de uma sociologia das formas do crítico literário Franco Moretti para os estudos em jornalismo. A discussão sustenta-se em duas hipóteses de fundo extraídas da obra do autor: i) determinado padrão estético-expressivo apenas se dissemina socialmente quando encontra respaldo em padrões culturais mais amplos; e ii) o processo de codificação simbólica desses padrões culturais não se dá apenas no plano do conteúdo, mas sobretudo na própria forma, na dimensão estético-expressiva da narração. Na sequência, elencam-se seis pressupostos teórico-metodológicos do autor passíveis de um diálogo interdisciplinar com o campo jornalístico.

Palavras-chave: Jornalismo, sociologia das formas, Franco Moretti

\begin{abstract}
The paper presents notes about the theoretical-methodological contribution of literary critic Franco Moretti's sociology of forms to journalism studies. The discussion supports itself on two background hypotheses from the author's work: i) certain aesthetic-expressive pattern just disseminates itself when it finds support on broader cultural patterns; ii) the symbolic codification process of such cultural patterns do not stablish only on content plan, but on own form, on the aesthetic-expressive dimension of narration. Moreover, the article lists six theoretical-methodological premises for an interdisciplinary interface with journalistic field.
\end{abstract}

Keywords: Journalism, sociology of forms, Franco Moretti 
${ }^{2}$ A crônica $A$ velhinha contrabandista encontra-se em diversas coletâneas. Utiliza-se, neste artigo, uma versão de 1979 com seleção de crônicas de Sérgio Porto sob o pseudônimo de Stanislaw Ponte Preta.

${ }^{3}$ A partir de uma pesquisa empírica, os autores dinamarqueses colocam-se como os primeiros teóricos a formalizar no ambiente acadêmico a existência uma tipologia para os parâmetros orientadores da seleção de notícias.

${ }^{4} \mathrm{O}$ livro Deciding what's news, de Herbert J. Gans, foi originalmente publicado em 1979. Utiliza-se aqui a edição comemorativa ao $25^{\circ}$ aniversário da publicação original. Ver Gans (2004).

\section{PARA SITUAR O DEBATE}

$\mathrm{H}$ Á UMA ANTIGA anedota, traduzida em crônica por Sérgio Porto sob a alcunha de Stanislaw Ponte Preta ${ }^{2}$, que narra a odisseia de uma velha senhora, experiente contrabandista, que costumava cruzar diuturnamente uma fronteira qualquer pilotando uma lambreta com produtos diversos na bagagem. Não tardou para que a presença nada insuspeita da contraventora incomodasse um atento fiscal de alfândega, que não media esforços, sempre sem sucesso, para localizar o foco do contrabando. Dia após dia, identificava-se um produto diferente; e o conteúdo da bagagem nunca denunciava o crime da habilidosa contrabandista. Moral da história: de tanto olhar o recheio da bagagem, o fiscal não se atentara para o cerne do contrabando. O descaminho estava na própria embalagem, ou seja, nas motocicletas que a velhinha conduzia.

A lição nada insigne da personagem de Stanislaw Ponte Preta é digna de provocação no contexto da presente discussão na medida em que constitui mais do que uma mera metáfora. Trata-se mesmo de uma caricatura para os diferentes ângulos de análise de algumas das principais tradições teóricas dos estudos em jornalismo, sobretudo daqueles voltados à compreensão das notícias. Por que as notícias são como são? O questionamento retórico presente nas reflexões de autores de diferentes épocas e escolas - a saber, do clássico estudo inspirado em equações matemáticas de Galtung e Ruge $(1965)^{3}$, passando pela abordagem sociológica de Herbert Gans (2004) ${ }^{4}$ no contexto norte-americano e aportando nos trabalhos europeus de recepção significativa no Brasil, como as obras de Nelson Traquina (2008) e Mauro Wolf (2003) - conformam uma matriz de formulações teóricas que valorizam a substância constitutiva das notícias, em suma, voltam-se a classificações a partir do conteúdo - ainda que não desconsiderem, de maneira rasa, outras perspectivas.

Reconhece-se, nesse sentido, numa analogia ao deslocamento metodológico proposto por Martín-Barbero (2003), a pertinência da mudança no lugar das perguntas - sem que se recaia no erro da paralaxe - passando da singularidade dos acontecimentos noticiosos, substância constitutiva da narração jornalística, para a compreensão das notícias como formas simbólicas em seu sentido ampliado. Ainda assim, evidentemente, não se trata de negligenciar o avanço no estado da arte de outras reflexões bastante substanciais para o campo jornalístico - destaca-se, nesse sentido, a leitura marxista de Genro Filho (2012) para os conceitos de singularidade e de particularidade; a compreensão de Schudson (2003) das notícias como narrativas; e o olhar para a narração jornalística de Sodré (2009) em paralelo às pontuações rítmicas do cotidiano, entre outras. Pelo contrário, o que se propõe aqui, no interim das peculiaridades de um artigo, é mais um 
suspiro de avanço para o estado da arte do campo. Busca-se a valorização do sentido social das formas simbólicas - adotando-se desde já o entendimento das notícias nesse espectro - tal como trabalhado nos estudos de objetos literários de György Lukács (2010), mas também a partir do aperfeiçoamento pela sociologia das formas do teórico italiano Franco Moretti, foco deste trabalho.

Nesse sentido, um dos principais interlocutores de Moretti ao redor do mundo, o crítico literário Roberto Schwarz (2012), ao recorrer à perspectiva de Lukács para textos ficcionais, é bastante preciso:

Não que os conteúdos não sejam sociais, mas a forma, ao trabalhá-los e organizá-los, ou também ao ser infletida por eles, configura algo de mais geral, análogo à precedência da sociedade sobre os seus conteúdos separados. Se as obras interessam, é porque se organizam de um modo revelador, que algum fundamento tem na organização do mundo histórico. (Ibid.: 288)

Não é por acaso que o crítico literário nascido na Áustria e radicado no Brasil, autor do ensaio sobre Memórias Póstumas de Brás Cubas na coletânea O Romance, organizada por Franco Moretti ${ }^{5}$, seja um dos principais interlocutores do teórico italiano em seus estudos sobre as formas literárias ${ }^{6}$. Interlocutor também de Antonio Candido - com quem conviveu na Universidade de São Paulo em meados dos anos 1960 -, Schwarz consagra seu trabalho no campo das ciências sociais e particularmente no terreno da crítica literária no Brasil, a partir de uma chave de compreensão que faz interface com a perspectiva analítica de seus interlocutores: o casamento entre a análise estilística e a reflexão histórico-social ${ }^{7}$. Este é certamente um dos pontos de intersecção entre a obra de Schwarz e o investimento teórico-metodológico de Moretti para o estudo das formas simbólicas.

O objetivo deste trabalho, nesse contexto, é desenvolver uma discussão teórico-metodológica a partir de apontamentos iniciais sobre a contribuição da sociologia das formas de Franco Moretti para os estudos teóricos em jornalismo e, especialmente, para o campo de estudo das notícias. Esses apontamentos não se constituem definitivos, tampouco conclusivos, uma vez que se trata de um primeiro esforço sistematizado para aproximar o arcabouço teórico e metodológico do autor italiano a um campo que dialoga com sua obra - em aproximações e distanciamentos, mas sobretudo em tensionamentos -, porém que não está no centro de sua mirada analítica. Como percurso, os apontamentos aqui sistematizados baseiam-se em três obras do crítico literário italiano: "A alma e a harpia" (1983) e "O século sério" (2001) ${ }^{8}$, ensaios presentes em compilações mais abrangentes do autor, e o livro O burguês $(2014)^{10}$, além de trabalhos de alguns de seus interlocutores, comentadores e críticos.
${ }^{5}$ A coletânea organizada por Franco Moretti, que reúne ensaios de especialistas de diversas partes do mundo, foi originalmente publicada em italiano abrangendo cinco vastos volumes. Dois volumes já foram publicados em língua inglesa, nos Estados Unidos, incluindo a versão na qual consta o ensaio de Schwarz sobre Machado de Assis. No Brasil, apenas um dos volumes, com o subtítulo A cultura do romance, foi publicado em 2009 pela editora Cosac Naify.

${ }^{6}$ Além da participação como colaborador na coletânea O romance, Roberto Schwarz possui uma recepção significativa na obra mais geral de Franco Moretti.

${ }^{7}$ Ver, nesse sentido, a obra Martinha versus Lucrécia (Schwarz, 2012), mas também a entrevista concedida por Roberto Schwarz a André Botelho e Lília Schwarcz para a Revista Brasileira de Ciências Sociais (Schwarz; Botelho, 2008).

${ }^{8}$ Originalmente datado de 1983. Na versão publicada no Brasil, o ensaio compõe a coletânea Signos e estilos da modernidade. Ver Moretti (2007).

${ }^{9}$ Originalmente datado de 2001, o ensaio "O século sério" possui três versões publicadas no Brasil. A primeira delas, utilizada neste trabalho, data de 2003 e foi publicada na edição n. 65 da Revista Novos Estudos do Centro Brasileiro de Análise e Planejamento.

${ }^{10}$ No Brasil, o livro foi publicado no ano seguinte. Ver Moretti (2014). 


\section{A MIRADA DE MORETTI}

No posfácio de Fama \& anonimato, consagrada coletânea do jornalista norte-americano Gay Talese publicada no Brasil, o escritor Humberto Werneck (2004) sugere que as notícias, em suas formas mais cruas, não possuem como premissa a necessidade de apresentarem-se como "palatáveis" ao público:

Não há, no que escreve Gay Talese, nada que não tenha sido pinçado da realidade e exaustivamente checado e conferido antes de baixar no papel. É jornalismo. Mas não o jornalismo usual, predominante, esse em que o repórter, em nome da imprescindível busca da objetividade, se sente desobrigado de servir ao leitor mais que uma pilha de informações descarnadas - como se fosse isso a realidade. Como se a informação devesse ser, goela abaixo do leitor, uma espécie de pílula para astronauta, que nutre sem a obrigação de ser palatável. Como se, provindos da mesma raiz latina, saber e sabor não pudessem andar juntos. (Ibid.: 524)

Na condição de posfácio da obra de Talese, como seria natural, a discussão estabelece-se no cenário comparativo entre os limites do jornalismo e de suas interfaces com a literatura - particularmente, em torno da retórica da sedução. Em última análise, no entanto, a hipótese de Werneck (2004) coloca-se em sentido diferente ao que se argumenta na presente reflexão a partir do ponto de vista de Franco Moretti. Isto é, se as formas simbólicas em geral são importantes como objeto de estudo - e aqui se reconhece a notícia como forma simbólica hegemônica de narração do cotidiano ao menos desde a virada do século XIX para o século XX nos modos de sociabilidade do mundo ocidental -, elas importam na medida em que encontram ressonância em elementos extralinguísticos presentes na vida privada e na vida cotidiana.

Localiza-se, em termos históricos, portanto, a primeira hipótese de fundo do autor, cara aos estudos das notícias: "quando uma novidade tão prosaica e modesta consegue difundir-se por toda a parte, deve haver algo na cultura circunstante que se encontra em profunda sintonia com ela" (Moretti, 2003: 15). A afirmação, evidentemente, não se destina originalmente ao universo das notícias. No extrato em questão, o crítico literário se refere às especificidades de determinada modalidade do romance europeu novecentista. Em termos teórico-metodológicos, todavia, a visão de Moretti denota um pressuposto mais abrangente, ou seja, trata-se da compreensão de que determinado padrão estético-expressivo apenas se dissemina socialmente quando encontra respaldo em padrões culturais mais amplos pavimentados nos universos da vida privada e da vida cotidiana. Nas palavras do autor, constitui-se uma espécie de "prazer narrativo", seja por parte dos enunciatários 
em consumi-lo, e, por conseguinte, remete-se a algo "palatável”, ou por parte dos enunciadores em operá-lo.

Faz-se possível afirmar, nesse interim, que se as notícias - como formas simbólicas - disseminam-se socialmente como se disseminaram ao longo do último século no modo de sociabilidade moderno, essa dinâmica se estabelece - parafraseando uma vez mais Moretti - a partir da constituição de "soluções imaginárias" no plano expressivo para "contradições reais" no plano da vida cotidiana. Diz o autor ao referir-se ao terreno da literatura:

Ainda penso na literatura como uma forma de "compromisso", de ajuste simbólico possível, de "solução" para os conflitos de uma época. Creio que, de fato, os romances permitem às pessoas se sentirem menos desconfortáveis em meio a esses seus conflitos. Geralmente os historiadores literários buscam uma explicação para esse aumento de vendas de livros na própria estrutura dos romances - que seriam mais bem escritos, mais realistas, mais interessantes para os leitores, e por aí vai. Procurei uma explicação alternativa para o fato de, de repente, os romances venderem mais. Defendi que a razão deve ser semelhante àquela que levou, no mesmo período, a uma produção e a um consumo maior de relógios, por exemplo. (Cariello, 2009)

A abordagem teórico-metodológica do autor não escapa ao seu lugar de fala. Natural de Sondrio, na Lombardia, Franco Moretti doutorou-se bastante jovem em Literatura Moderna pela Universidade de Roma, em 1972. Oriundo de uma família de proeminência no cenário artístico-intelectual na Itália - seu irmão, o cineasta Nanni Moretti, destacou-se pela direção de filmes consagrados internacionalmente, como O quarto do filho (2000) e Habemus Papam (2011) -, Franco Moretti passou a ser reconhecido fora do continente europeu, tornando-se professor visitante nas universidades norte-americanas de Berkeley, Duke, Ucla e San Diego. Radicado nos Estados Unidos, responde atualmente pela cadeira de Literatura Inglesa na Universidade de Stanford. No campo da pesquisa, uma de suas iniciativas de maior fôlego foi a organização da série O romance, coletânea em cinco volumes que reúne ensaios de estudiosos do gênero provenientes de diferentes partes do mundo. O autor também é um dos principais colaboradores do periódico New Left Review.

Marxista em sua filiação político-intelectual, Moretti projeta forte ênfase na análise histórica de seus objetos de estudo. Do ponto de vista da formação, conforme argumenta o crítico McKenzie Wark (2013), ao passo em que possui como seus principais predecessores pensadores marxistas italianos pouco conhecidos fora do contexto europeu, como Galvano Della Volpe e Lucio Colletti, Moretti baseia-se na fase madura de sua crítica em alguns dos principais expoentes da 
${ }^{11}$ No original: "forms are the abstract of social relationships: so, formal analysis is in its own modest way an analysis of power". Tradução do autor. tradição crítica, de György Lukács e Antonio Gramsci a Raymond Williams e Roland Barthes.

Inspirado na teoria literária de Lukács, Moretti compreende que "as formas são adensamentos das relações sociais: assim, a análise formal é, em sua modesta maneira, uma análise do poder"11 (apud Wark, 2013). Nesse sentido, o autor volta-se menos a cenários e personagens do que à estruturação rítmica das narrativas. Seu aparato teórico-metodológico busca, como num movimento de passo atrás, rastrear o significado de palavras-chave substanciais e a textura de tipos particulares de formas de organização da narração - métodos muitas vezes controversos no universo dos estudos literários (Wark, 2013). É nesta conjuntura que se localiza a segunda hipótese extraída de Moretti como contribuição para os estudos teóricos do jornalismo.

\section{A SEGUNDA HIPÓTESE}

$\mathrm{Na}$ empiria de seus estudos, Franco Moretti apresenta como foco os romances europeus novecentistas, sobretudo aqueles que perpassam as nuances do ideário burguês. Em termos históricos, trata-se de um estilo narrativo contemporâneo à ascensão da narração noticiosa do cotidiano no modo moderno de sociabilidade ocidental. Isto é, o jornalismo, que floresce no século XVII europeu a partir da confluência de fatores como o desenvolvimento da tipografia gutemberguiana, a expansão dos mecanismos técnicos que possibilitam um inédito fluxo de informação e a consequente transformação desse fluxo em mercadoria no seio de uma economia em expansão (Sousa, 2004), assiste, já no porvir do século XIX, à configuração de uma nova modalidade de opinião pública que demanda daqueles antigos compêndios noticiosos um mergulho no cotidiano.

Nesse aspecto, por se debruçar sobre a lógica dos romances burgueses novecentistas, Moretti não casualmente vale-se como opção retórica da utilização de exemplos extraídos da própria representação ficcional da narração jornalística pela narrativa literária. O caso de Ilusões perdidas, obra clássica do francês Honoré de Balzac dissecada pelo crítico italiano em suas análises, é significativo nesse sentido. Tome-se um extrato de "O século sério" como exemplo:

Balzac, segunda parte das Ilusões perdidas (1839). Lucien de Rubempré está escrevendo (finalmente!) o seu primeiro artigo, que constituirá uma verdadeira "revolução no jornalismo". É a oportunidade que ele espera desde o dia em que chegou a Paris. Mas nas pregas desse episódio esconde-se um outro: o jornal está sem artigos, qualquer coisinha serve, rápido, não importa sobre o quê, basta preencher os espaços em branco; e um amigo de Lucien, introduzido por uma 
vírgula despretensiosa, põe-se também a escrever. É quase a ideia platônica do enchimento romanesco: um trecho que preenche um pouco de espaço, nada mais. (Moretti, 2003: 24)

No caso em questão, trata-se de uma problematização - pela via da metáfora do jornalismo - sobre como a narração do cotidiano passa a preencher as cenas folhetinescas dos romances burgueses. Uma vez mais, Moretti reforça uma inversão metodológica para a análise da relação histórica entre literatura e jornalismo: não mais a literatura como parâmetro histórico para explicar, ou mesmo adjetivar, o jornalismo, mas o jornalismo como parâmetro - pela metáfora do enchimento das páginas - para explicitar a literatura; inversão levada a cabo justamente por um crítico literário sem trânsito pelo universo da não ficção.

A relação, evidentemente, é tensionada. Tome-se novamente o exemplo de Gay Talese. No prefácio de $O$ reino e o poder, livro sobre a história do The New York Times, o jornalista demarca posição:

Em cada um dos meus livros há um fascínio pelas verdades mais obscuras da natureza humana, um desejo de ir além da fachada e tocar os nervos e as nuances da vida privada. Há muito acredito que o realismo é fantástico, que os sonhos e impulsos da América moderna, se narrados com exatidão, podem ser tão socialmente significantes e historicamente úteis quanto as vidas e situações fictícias criadas por dramaturgos e romancistas. (Talese, 2000: 9, grifos nossos)

"O realismo é fantástico" e os "sonhos e impulsos", caso sejam "narrados com exatidão", aproximam-se de características tão fundamentais quanto "situações fictícias criadas por dramaturgos e romancistas". Ficção versus exatidão para aportar-se na compreensão da realidade em suas entranhas e nuances. Não por acaso, Moretti e Talese costumam utilizar as concepções de vida privada e de vida cotidiana para sustentarem e justificarem suas opções analíticas e metodológicas. A diferença, contudo, parece estar novamente no deslocamento do lugar das perguntas. Enquanto a narração detalhada - "com exatidão" - das "verdades mais obscuras da natureza humana” são substanciais a Gay Talese e sua busca se dá metodologicamente por meio do mergulho no privado e no cotidiano, Franco Moretti observa na ritmização e nos ritos (muitas vezes ocultos) entranhados na vida privada e na vida cotidiana as chaves explicativas (ou palavras-chave, como será mencionado à frente) para a disseminação social de determinadas formas simbólicas e de estilos narrativos. Em "A alma e a harpia”, por exemplo, o autor italiano recorre a um texto clássico de Lukács, publicado originalmente em húngaro no início do século XX, para reforçar seu ponto de vista: 
${ }^{12}$ Argumenta Moretti (2003: 17): "com efeito, esse é exatamente o mundo do romance burguês, mas não por seus conteúdos [...] destes, ao contrário, se fala muito pouco: é por meio do enchimento que a lógica da racionalização atua sobre a forma mesma do romance, $o$ seu ritmo narrativo".

A forma é sociológica não só como elemento mediador, como princípio que conecta autor e receptor, tornando a literatura um fato social, mas também em relação com o material a ser formado. [...] A forma, numa obra, é o que organiza, num todo fechado, a vida que lhe é dada como assunto, aquilo que determina seu tempo, ritmo e flutuação, sua densidade e fluidez, sua rigidez e suavidade; aquilo que acentua as sensações percebidas como importantes e distancia as de menor importância; aquilo que coloca as coisas no primeiro plano ou no plano de fundo e arruma-as em ordem. (Lukács, 1981: 69-71 apud Moretti, 2007: 24, grifos nossos)

Nesse contexto, a análise de Moretti - ainda que não focada particularmente na narração jornalística sob um vértice empírico - proporciona uma segunda hipótese teórico-metodológica pertinente aos estudos sobre a organização e a disseminação da narração noticiosa: o processo de codificação simbólica de padrões culturais mais amplos (e hegemônicos) presentes na vida cotidiana não se dá apenas no plano do conteúdo - aliás, nesse plano, em personagens e cenários, se dá muito pouco na perspectiva do crítico italiano ${ }^{12}-$, porém na própria forma, na dimensão estético-expressiva da narração. Não é à toa que Moretti faz questão de demonstrar que uma das premissas mais básicas da narração - "uma história merece ser contada se uma norma foi violada (uma norma moral ou probabilística, ou as duas coisas juntas), se apresenta um 'fato inaudito"' (Moretti, 2003: 9) - deixa ter protagonismo em determinado momento da história dos romances burgueses e vai ao segundo plano para dar lugar a uma dimensão mais determinante: a aderência a padrões culturais mais abrangentes (e menos inauditos) presentes na vida cotidiana.

\section{ALGUMAS "IDEIAS FORA DO LUGAR"}

Mas, afinal, o que pode ser compreendido pela ideia de padrão cultural - concepção-chave nas relações acima apresentadas - e de que padrões se fala quando estão em jogo os modos modernos de sociabilidade no qual se inscreve a narração jornalística?

Como forma de distinção metodológica, entende-se por padrão cultural o conjunto de elementos simbólicos que dialoga tanto com a noção teórica de valor cultural, da qual se distingue por sua maior abrangência, uma vez que um padrão cultural envolve diferentes variáveis socioculturais, quanto com a definição de "imaginário social" elaborada por Cornelius Castoriadis (1987: 229), com a qual compartilha seu processo constitutivo: "um sistema de normas, valores, linguagem, instrumentos, procedimentos e métodos de fazer frente às coisas e de 
fazer coisas". Desse modo, embora em sua acepção dicionarizada o substantivo padrão dilua-se em diferentes definições oriundas etimologicamente do termo latino patronus - "protetor", na tradução literal -, a ideia de padrão cultural aqui adotada não contradiz, por seu caráter não estanque, o complexo jogo de continuidades e descontinuidades presente na cultura. Em suma, como elucida Faro (2014: 100), trata-se de um elemento de natureza simbólica que "conforma a existência sensível" e, ao mesmo passo, concede a ela os componentes com os quais "o ser social lê e interpreta o mundo".

Ao abordar os modos modernos de produção capitalista sob uma ótica culturalista, Stuart Hall (1977: 317), em direção semelhante, aponta para a existência de uma complexa trama de estruturas e de relações sociais que se estabelece nos diferentes níveis de práticas cotidianas - conjuntura que culmina em uma padronização, um "modo de vida", que serve de parâmetro para indivíduos e grupos sociais. Segundo o autor, além dos próprios modos materiais de produção, essa trama envolve as formas de organização social do trabalho, o desenvolvimento técnico das atividades produtivas, as instituições sociais pelas quais ocorrem a circulação de bens e a percepção social de valores, bem como as formas de associação civil, de vida familiar e de estruturas políticas apropriadas a esse contexto. Consiste, em última análise, na configuração de um padrão de ordem cultural que dialoga com a concepção de hegemonia cunhada por Antonio Gramsci. Assume-se, nesse contexto, o pressuposto de que as relações sociais da modernidade são mediadas por padrões culturais hegemônicos tais quais os padrões de temporalidade e de objetividade que se entrecruzam na experiência cotidiana pela via da sociabilidade moderna - típicos de uma racionalidade substancialmente instrumental (Adorno; Horkheimer, 1985); instância pela qual se atrelam à vida cotidiana o domínio e o acesso controlado aos elementos que rompem com sua regularidade.

Isso posto, entende-se que o raciocínio de Franco Moretti, oriundo do campo da crítica literária, mostra-se também passível de interpretação no terreno do jornalismo. Ou seja, o padrão estético-expressivo do modo noticioso de narrar a realidade, neste caso, condiz com a dinâmica dupla de transcodificação e de disseminação de um sentido social de regularidade e de racionalidade decalcado na cultura. Busca-se novamente a contribuição de Roberto Schwarz:

A forma - que não é evidente e que cabe à crítica identificar e estudar - seria um princípio ordenador individual, que tanto regula um universo imaginário como um aspecto da realidade exterior. Em proporções variáveis, ela combina a fabricação artística e a intuição de ritmos sociais preexistentes. [...] O vaivém exige uma 
descrição estruturada dos dois campos, tanto da obra como da realidade social, cujas ligações são matéria de reflexão. (2012: 48)

Roberto Schwarz, assíduo interlocutor de Franco Moretti, é autor do ensaio "As ideias fora do lugar", publicado originalmente no Brasil em 1977 na coletânea Ao vencedor as batatas, livro cujo subtítulo não poderia ser mais apropriado ao presente debate: forma literária e processo social.

\section{A DIALÉTICA ENTRE FORMA E PROCESSO SOCIAL}

Schwarz (1977) debruça-se no ensaio aos desajustes - as "metamorfoses na semiperiferia do capitalismo", nas palavras de Moretti (2014) - entre os modelos ocidentais de desenvolvimento capitalista e a realidade brasileira no período de edificação de romances canônicos como as obras de Machado de Assis e José de Alencar; daí a contundente metáfora das "ideias fora do lugar". Num movimento epistemológico, contudo, as ideias fora do lugar são aqui interpretadas não como "malformações" ou "metamorfoses", a exemplo do contexto original, mas como contribuição possível de um arcabouço teórico-metodológico (um modo de análise) desenvolvido por Moretti no campo da crítica literária para o terreno dos estudos teóricos em jornalismo.

Faz-se pertinente recordar, nesse sentido, que Franco Moretti costuma utilizar com propriedade em suas análises retóricas outras formas simbólicas para além da literatura como exemplos para demonstrar a codificação, no terreno expressivo, de valores presentes na esfera da vida cotidiana. Os quadros do pintor holandês Johannes Vermeer, explorados com propriedade no ensaio "O século sério", são casos significativos nesse aspecto. O crítico McKenzie Wark (2013), ao debruçar-se sobre a obra de Moretti, é também preciso ao mencionar a aplicação do método analítico do autor italiano em outros objetos que respondem aos modos de organização da vida cotidiana em termos contemporâneos:

Este mundo [do século XXI] não apresenta mais lugar para o romance burguês, tampouco para o detentor de sua chama hermenêutica - o crítico literário - pela simples razão de que não é mais um mundo burguês. Nossa classe dominante ainda vive a explorar o trabalho [das classes subalternas], mas, em termos culturais, não é burguesa. A forma literária em que se revela melhor é provavelmente o livro de autoajuda ou a biografia de negócios. Tais formas provavelmente renderiam ideias interessantes se reunidas e estudadas como um vasto banco de dados, exceto pelo fato de que tais textos, ao contrário dos romances largamente esquecidos e fora 
de moda analisados por Moretti, são zelosamente protegidos como "propriedade intelectual"13. (Wark, 2013, grifos nossos)

Nessa linha de raciocínio, alguns dos principais pressupostos teórico-metodológicos de Franco Moretti podem ser apresentados como contribuições factíveis ao universo extraliterário - e particularmente ao campo dos estudos em jornalismo, foco da presente discussão. Trata-se, para valer-se uma vez mais da referência de Schwarz (1977), de ideias deslocadas de seus lugares originais, mas não em seu sentido anômalo e descontextualizado.

\section{OS PRESSUPOSTOS TEÓRICO-CONCEITUAIS DE MORETTI}

Franco Moretti desenvolve seu estilo analítico com afinidade na retórica da argumentação e mobiliza seu arcabouço teórico-metodológico na construção de uma "história social das formas literárias" (Chagas, 2013: 194). O fôlego investido na organização dos cinco volumes de $O$ romance, coletânea que reúne estudiosos de diferentes partes do mundo, demonstra esse empenho.

Em estudo sobre a metodologia analítica de Moretti, Dolabela Chagas (2013) elenca quatro pressupostos presentes na retórica do crítico literário italiano aos quais serão aqui adicionadas outras duas premissas - que possibilitam um diálogo como forma de contribuição interdisciplinar com o campo do jornalismo:

\section{i) Desconforto com o caráter supra-histórico e autônomo das formas simbólicas quanto às determinações sociais}

Para Moretti (2007: 22), "o conhecimento do contexto sócio-histórico de uma obra ou gênero literário” não constitui um “extra’ a ser mantido à margem da análise retórica”, uma vez que "os textos literários são produtos históricos organizados segundo critérios retóricos". Essa perspectiva analítica demonstra o "desconforto de Moretti com as aporias decorrentes da longa dominância, na crítica e na historiografia literária, de certos pressupostos conceituais e metodológicos de origem iluminista e romântica"; a saber: o caráter supra-histórico, antinstitucional e esteticamente desviante da literatura, a autonomia do artista "gênio" quanto às determinações sociais, além da recorrência como maior exemplaridade das "grandes obras" como casos de um sistema totalizador (Chagas, 2013: 195). O desconforto do crítico italiano remete, em última instância, à dicotomia entre as tradições do formalismo e do historicismo interpretadas como caricaturais por Schwarz em entrevista a Schwarcz e Botelho (2008: 156). Roberto Schwarz, aliás, é enfático ao mencionar o legado de Antonio Candido
${ }^{13}$ No original: "Such a world has no place for either the bourgeois novel or the keeper of its hermeneutic flame, the literary critic, for the simple reason that it is no longer a bourgeois world. Our ruling class still lives by exploiting labor, but in cultural terms it is not bourgeois. The literary form in which it reveals itself best is probably the self-help book or the business biography. Such forms would probably yield interesting insights if amassed together and studied as one vast database, except that such texts, unlike the largely forgotten and out-of-print novels Moretti analyzes, are zealously guarded 'intellectual property"'.

Tradução do autor. 
no Brasil como exemplo de superação do reducionismo dessa dicotomia. Franco Moretti, inspirado em autores de base marxista, como György Lukács e Raymond Williams, também demonstra escapar do pensamento dicotômico pela via da dialética, mas ressalta que o caráter social de uma obra se localiza eminentemente em sua forma simbólica. Do ponto de vista da contribuição interdisciplinar para o campo jornalístico, o pressuposto projeta luz à pertinência de se observar os estudos teóricos sobre as notícias para além de análises meramente conteudísticas (como as categorizações de valores-notícia), que não raramente negligenciam o caráter estético-expressivo da narração noticiosa, bem como de análises concentradas no formalismo supra-histórico dos periódicos (os estudos funcionalistas de gêneros jornalísticos que não ultrapassam os limites da mera classificação, por exemplo) e as historizações devotadas exclusivamente aos veículos hegemônicos.

ii) Ênfase nos componentes não literários da literatura / Compreensão do locus de especificidades da literatura a partir do manejo simbólico de conteúdos sociais sob códigos estéticos

Diz Moretti (2007: 34) que o "fenômeno extraliterário nunca é mais ou menos importante como 'objeto' ou 'conteúdo' possível de um texto, mas sim devido ao seu impacto sobre os sistemas de avaliação, e, portanto, sobre as estratégias retóricas". O crítico literário desenvolve uma crítica aos corolários da "ambiguidade", da "polissemia" e da "não referencialidade" como caução de "artisticidade" do texto literário. Nas palavras de Dolabela Chagas (2013: 196),

Ao invés, então, de identificar na imanência do "texto" os índices de "literariedade" da literatura - como boa parte da crítica do século XX - Moretti enfatizaria os componentes não literários da literatura ao estender à sua análise a retórica argumentativa: no manejo retórico-argumentativo dos conteúdos sociais sob códigos estéticos selecionados se revelariam muitas das especificidades da literatura como discurso.

No caso do jornalismo, a referencialidade e a verossimilhança, por si só, já consistem em pressupostos básicos, muito embora sob o paradigma histórico do modelo hegemônico de jornalismo informativo (o chamado hard news na tradição norte-americana), outros corolários semelhantes sejam disseminados - não raramente sob as limitações de um realismo irrefletido - como caução da garantia da deontologia jornalística no texto noticioso. Pois bem, numa leitura interdisciplinar, valendo-se de uma adaptação das palavras 
de Chagas (2013: 196), entende-se que no "manejo retórico-argumentativo dos conteúdos sociais sob códigos estéticos selecionados" pode-se verificar as revelações de "muitas das especificidades" do jornalismo como discurso social. O trabalho historiográfico de Michael Schudson (1978) demonstra-se representativo nesse aspecto. Ao voltar-se ao estudo histórico dos jornais norte-americanos (modelo hegemônico de prática jornalística caro ao modo ocidental), o sociólogo, de modo geral, debruça-se sobre a matriz histórica (os componentes não jornalísticos do jornalismo) de alguns dos principais paradigmas da prática noticiosa (a ideia de objetividade tratada como valor ideológico disseminado após a Primeira Guerra Mundial, por exemplo) ao invés de meramente elencar e concatenar o surgimento histórico de veículos e técnicas. Remete-se, portanto, ao manejo simbólico de conteúdos sociais sob códigos estéticos.

iii) Integração das formas simbólicas às trocas culturais regulares pavimentadas na vida cotidiana / Isonomia entre valores culturalmente sancionados e formas simbólicas socialmente disseminadas

Em “A alma e a harpia”, Moretti (2007) propõe a análise da produção literária fora dos liames fechados da obra e do texto. Conforme explicita Chagas (2013: 198), “obra' seria a produção 'plena em si mesma' de um autor singularizado em seu contexto histórico e social; 'texto' seria a matéria objetualizada em sua autonomia quanto àquele contexto e quanto à sua própria autoria”. Moretti procura romper com essa dicotomia. Para o autor,

Uma história da literatura capaz de reescrever-se como sociologia das formas simbólicas, como história das convenções culturais, talvez pudesse encontrar finalmente um papel e uma dignidade no contexto de uma história total da sociedade. (Moretti, 2007: 33)

Em outros termos, o crítico italiano trabalha com a proposição de que, para além das amarras da obra e do texto, a literatura, "integrada a trocas culturais regulares, atuaria como instância de provocação efetiva do leitorado por meio de do manejo de lugares-comuns, consensos e valores socialmente disseminados" (Chagas, 2013: 198). Do ponto de vista interpretativo, Moretti (2007) advoga em favor de uma "isonomia" entre valores culturalmente sancionados e símbolos socialmente consensuais. Nesse sentido, reconhece-se aqui um dialogismo entre a proposição do crítico literário e a analogia proposta por Muniz Sodré entre a prática jornalística e a pontuação rítmica de uma composição musical. 
Detalha o autor brasileiro: "os microaspectos do fato, como as notas, fluem ritmicamente dentro de uma 'métrica', que é a temporalidade marcada como 'o cotidiano"' (Sodré, 2009: 92). Por sua vez, essa pontuação rítmica possui intervalos cíclicos diferenciados, o que leva toda notícia a ter "um ciclo cuja duração varia, na prática, de acordo com o valor jornalisticamente atribuído ao fato" (Sodré, 2009: 94). De seu turno, Franco Moretti recusa-se a hierarquizar a literatura como uma "produção cultural elevada" e enfatiza seu elo com "padrões e expectativas contextuais em sua disposição de fazer o leitor 'sentir-se à vontade' em seu mundo" (Chagas, 2013: 198). Em "O século sério", ao discorrer sobre o padrão cultural de seriedade que se pavimentava na vida cotidiana da burguesia europeia em meados do século XIX e sobre sua codificação simbólica pela literatura, o autor mostra-se bastante ilustrativo:

Mas o que exatamente significa "sério" em literatura? Para Diderot, que introduz o genre sérieux em 1757, nos Diálogos sobre o filho natural, trata-se de uma forma intermediária entre a tragédia e a comédia. É uma intuição genial. Porque efetivamente, com o advento do ethos sério, e com a concomitante multiplicação dos enchimentos, o romance encontra um ritmo novo, tranquilo, um tipo de "neutralidade" narrativa que lhe permite funcionar sem ter de recorrer sempre a medidas extremas. Escreve-se e lê-se com um espírito novo, prosaico, sem esperar coisas inauditas a cada volver de página. (Moretti, 2003: 8)

Levar o enunciatário a "sentir-se à vontade em seu mundo", com uma "neutralidade narrativa" que o conduz, sem esperar sustos, "a cada volver de página". Nessa perspectiva, a passagem diz muito a respeito de um universo que também é peculiar à narração jornalística do cotidiano. Para valer-se novamente da analogia de Sodré (2009: 94), os "microaspectos do fato" que, "como as notas, fluem ritmicamente dentro de uma métrica", ressoam entre as expectativas e consensos da vida cotidiana - tal como será visto no próximo pressuposto.

iv) Valorização do papel da literatura como discurso afirmador de valores (convenções estéticas integradas a repertórios comuns)

Remete-se neste ponto, uma vez mais, à primeira hipótese de fundo levantada no artigo: um padrão estético-expressivo (um modo de narrar o mundo) apenas se dissemina socialmente se encontrar respaldo em padrões culturais mais amplos presentes na vida cotidiana. A respeito da perspectiva análise de Franco Moretti, Chagas (2013: 199-200) discorre: 
Se, na modernidade, a literatura se firmou como uma instância u-tópica de harmonização das tensões provocadas pela fragmentação das estruturas sociais de sentido, a própria necessidade do acordo resultava de uma complexificação da vida social cujo potencial de desorientação teria impelido à busca, na ficção, de conciliações indisponíveis no "mundo da vida": a literatura ofereceria ao público a experiência de soluções quase impossíveis na prática, mas compartilháveis afetivamente, o seu sucesso advindo do seu pertencimento pragmático às rotinas sociais, e não do seu distanciamento pela criticidade ou pela negatividade estética.

Pois bem, volta-se novamente à concepção de "pontuação rítmica do cotidiano" defendida por Sodré (2009). Na narração jornalística do cotidiano, entende-se que complexidade do "mundo da vida", para valer-se da expressão de Moretti, reduz-se no modelo hegemônico de jornalismo à singularidade do fato jornalístico e a sua explicação pautada pelos elementos do atual - o aqui e o agora caracterizadores dessa narração. Essa dinâmica de caráter simbólico é mediada por elementos estético-expressivos que encontram respaldo nos padrões culturais da experiência cotidiana moderna, em sua racionalidade e regularidade. Constituem exemplos relevantes da sistemática em questão a própria utilização do lead jornalístico - o que, quem, quando, por que e como -, elemento sintomático da singularização dos acontecimentos pelo jornalismo moderno, ou, de modo mais específico, a presença de estatísticas e de gráficos para explicitar - de modo racional e matemático - o desenrolar de fatos singularizados. Como ressalta Moretti (2003: 8), "escreve-se e lê-se com um espírito novo, prosaico, sem esperar coisas inauditas a cada volver de página”. Para os consumidores tradicionais de notícias, consiste na tarefa diária de "virar a página" do jornal e visualizar, uma após a outra, abordagens "racionais e objetivas", segmentadas em cadernos e seções, dos acontecimentos cotidianos sem se deparar - dia após dia - com surpresas drásticas que não tenham sido devidamente singularizadas e esmiuçadas pela narração.

v) Compreensão da forma como raiz social definitiva que penetra na vida cotidiana

O pressuposto endereça novamente às duas hipóteses de fundo anteriormente destacadas. Para Franco Moretti, a disseminação social de uma forma simbólica se estabelece em um ambiente penetrado por convenções comuns localizadas na vida privada e na vida cotidiana; trata-se de um olhar analítico que observa a organização estética de conteúdos a partir de convenções sociais prévias. Em "A alma e a harpia", ao discutir a teoria literária de Lukács, o autor 
sublinha que a ideia de "convenção" constitui um "conceito fundamental porque indica quando uma forma assumiu uma raiz social definitiva, penetrando na vida cotidiana, animando e organizando-a de maneira cada vez mais imperceptível e regular - e, portanto, mais eficaz" (Moretti, 2007: 25). As concepções de "imperceptível", "regular" e "eficaz" podem ser compreendidas em paralelo ao conceito gramsciano de hegemonia. Nesse sentido, a forma hegemônica com a qual o jornalismo conduz a narração do mundo da vida (organização estética de conteúdos) também se estabelece em diálogo com convenções sociais prévias presentes na vida cotidiana a partir de matrizes culturais históricas. O trabalho de Michael Schudson (1978) de constituir uma história do jornalismo norte-americano a partir de uma leitura de passo atrás - "vista de longe", para utilizar uma expressão de Franco Moretti - com base na disseminação de valores disseminados na sociabilidade ocidental é significativo nesse aspecto. Todavia, uma contribuição ainda mais enfática parece ser a de Martín-Barbero (2003), no capítulo "O longo processo de enculturação", ao estabelecer desde a Idade Média as matrizes históricas da mediação massiva que irão pavimentar o terreno para a difusão moderna de linguagens como o melodrama e o próprio jornalismo.

vi) Entendimento da história das formas estéticas como componente de uma história dos valores e das estruturas de pensamento

Franco Moretti desenvolve uma compreensão da literatura como "um tipo de discurso que, apesar de regido por valores, convenções e códigos próprios, se coloca em meio às demais produções culturais, não sendo nem mais nem menos 'especial' ou 'importante"' (Chagas, 2013: 209). De forma consonante, em "A alma e a harpia", o autor defende que:

Um procedimento artístico assume seu significado total não à luz de outros fenômenos artísticos, mas sim dos produtos do pensamento científico e filosófico. Na verdade, é na correlação com estes últimos que sua "forma" se torna compreensível e revela sua própria função cultural. (Moretti, 2007: 31)

Por conseguinte, uma história das formas estéticas - ou dos padrões estético-expressivos, para fazer jus a uma nomenclatura mais apropriada ao universo extra-artístico - não se estabelece fora do escopo mais abrangente da história das estruturas hegemônicas de pensamento. Essa premissa encontra forte aderência no já mencionado trabalho desenvolvido por MartínBarbero (2003) ao voltar-se às matrizes históricas da comunicação massiva. Encarada sob a perspectiva culturalista do autor latino-americano, a valorização 
do conhecimento racional-objetivo nos modos modernos de vida - aspecto entendido como um componente essencial do "longo processo de enculturação" - encontra respaldo em elementos estruturadores da sociedade e projeta-se diretamente nas "transformações do saber e dos modos populares de sua transmissão" (Martín-Barbero, 2003: 144). Nessa direção, entre outros exemplos, Martín-Barbero remete ao modo como historicamente a instituição "escola" desempenha "papel preponderante" no solapamento de uma consciência popular e no processo de desconstrução instituído pela racionalidade moderna contra o "saber mágico":

A aprendizagem da nova sociabilidade começa pela substituição da nociva influência dos pais - principalmente da mãe - na conservação e transmissão das superstições. E passa sobretudo pela mudança nos modos de transmissão do saber. Antes se aprendia pela imitação de gestos e através de iniciações rituais; a nova pedagogia neutralizará a aprendizagem ao intelectualizá-la, ao convertê-la em uma transmissão desapaixonada de saberes separados uns dos outros e das práticas. (Martín-Barbero, 2003: 145-146)

É nesse ponto que se sublinha um dos principais resultados decalcados na sociabilidade moderna pela secularização do conhecimento: a emergência do modo de experimentação do mundo determinado por uma racionalidade técnico-científica especialmente quantitativa, caracterizada pela calculabilidade e pela precisão matemática, na leitura sobre as coisas e sobre a natureza, operacionalização que resulta, como dito, no incremento da sensação de poder dos indivíduos sobre a natureza e sobre o próprio mundo. Pois bem, o desenvolvimento do modo jornalístico de se narrar a vida cotidiana a partir de uma deontologia própria (a pirâmide invertida, os critérios de noticiabilidade, as fontes como experts, os paradigmas da objetividade, da impessoalidade e da imparcialidade etc.) - calcado na regularidade e na racionalidade - não pode ser compreendido desentranhado desse modo de experimentação do mundo, isto é, fora de uma história de valores mais amplos e aderentes penetrados na vida cotidiana como estruturas de pensamento.

\section{ALGUMAS CONSIDERAÇÕES FINAIS}

Os pressupostos extraídos da obra de Franco Moretti e aqui interpretados como pertinentes para potencializar, numa perspectiva interdisciplinar, os estudos em jornalismo em termos teórico-metodológicos, integram um arcabouço mais abrangente e instigante (mas não menos controverso) conduzido pelo 


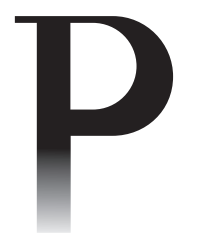

${ }^{14}$ Refere-se ao ensaio "Conjecturas sobre a literatura mundial”, publicado em 2001 numa coletânea organizada por Emir Sader.

autor italiano ao longo de sua trajetória acadêmica. Conforme revela o crítico literário Luís Augusto Fischer (2009), desde os primeiros trabalhos que colocam Moretti em evidência no Brasil ${ }^{14}$, é possível desnudar

o tamanho da briga que este italiano, especialista em romance inglês, comprava: nem mais, nem menos, estava repassando criticamente as principais alternativas concebidas até hoje na direção de uma história mundial da literatura. Nada óbvio, nada fácil. [...] [Moretti] não quer estudar estrutura narrativa em abstrato; sua batalha é com a empiria que estrutura os romances. Cidade, campo, a rua, a divisão das classes pelo espaço, proximidade ou distância, essas variáveis geográficas são convocadas em paralelo com o desenho dos enredos.

A ideia de metodologia em Franco Moretti é desafiadora na medida em que o autor se posta a observar a literatura "de longe", em perspectiva, "a ponto de poder discernir os grandes veios, as tendências, os caminhos" que o romance toma no decorrer da história (Fischer, 2009). Mais do que isso, porém, Moretti procura estabelecer um olhar que culmina - para além da crítica literária - numa sociologia das formas simbólicas. Esse é o ponto que mais interessa ao universo extraliterário, a exemplo do campo jornalístico e particularmente do terreno da notícia - forma simbólica privilegiada entre as formas de expressão que se disseminam no modo ocidental de sociabilidade moderna.

Ao voltar-se aos veios, tendências e caminhos, Moretti desenvolve metodologias próprias e uma retórica eficiente em suas análises. Em O burguês (Moretti, 2014), por exemplo, obra na qual se põe a estudar a "ascensão e queda" da figura da burguesia na literatura, o autor lança mão da busca incessante por "palavras-chave" - em termos lexicais - presentes nos estilos narrativos e que se instituem como chaves-explicativas fundamentais para a compreensão das mediações existentes entre os "valores culturalmente sancionados" e as "formas simbólicas socialmente disseminadas". Pelas limitações do presente artigo, voltado a apontamentos introdutórios sobre a contribuição da sociologia das formas de Moretti aos estudos teóricos do jornalismo, não se coloca como pretensão o desenvolvimento detalhado de tal perspectiva - o que deve ser realizado em um segundo momento. Todavia, o que são as ideias de "exatidão" e "realismo" decalcadas na autodescrição de Gay Talese, anteriormente citada, senão palavras-chave significativas que surgem como pistas para desvendar todo um conjunto de valores sociais sobre os quais se pavimenta a deontologia jornalística? Quantas e quais outras palavras-chave não podem ser identificadas no conjunto histórico da produção jornalística hegemônica que explicitem a disseminação social de conceitos como critérios de noticiabilidade, valores-notícia, apuração, 
furo jornalístico, deadline, entre outros? Trata-se, como dito, de assunto para uma nova discussão.

Por ora, convém destacar a factibilidade das hipóteses levantadas no artigo, bem como dos pressupostos teórico-metodológicos elencados, como contribuições para os estudos em jornalismo. Constitui-se, assim, uma linha de raciocínio semelhante à de Sodré (2009) quando posta em primeiro plano a concepção de cotidiano e compreende a narração jornalística no bojo de uma pontuação rítmica peculiar pautada pela temporalidade da produção capitalista. Consiste ainda numa maneira ampliada de interpretação do jornalismo - e das notícias - a partir de sua configuração estético-expressiva e de sua interface com valores culturais socialmente disseminados na vida cotidiana.

Finalmente, propõe-se uma leitura abrangente da narração jornalística como forma simbólica para além da restrição de sua explanação como obra ou como texto - no entendimento de Franco Moretti - tampouco para além da aridez da concepção estrita do conteúdo. Caso contrário, tal como o agente de alfândega da emblemática crônica de Stanislaw Ponte Preta (1979) que abre este artigo, corre-se o risco de se voltar o olhar demasiadamente ao contento do fenômeno sob pena de não conseguir enxergar a complexidade por trás de sua forma simbólica. M

\section{REFERÊNCIAS}

ADORNO, T. W.; HORKHEIMER, M. Dialética do esclarecimento: fragmentos filosóficos. Rio de Janeiro: Jorge Zahar, 1985.

CARIELLO, R. Aventuras modernas: entrevista com Franco Moretti. Folha de S.Paulo, São Paulo, 27 set. 2009. Caderno Mais! Disponível em: <http://bit. ly/2uh75zs>. Acesso em: $1^{\circ}$ mar. 2016.

CASTORIADIS, C. As encruzilhadas do labirinto: os domínios do homem. Rio de Janeiro: Paz e Terra, 1987. v. 2.

CHAGAS, P. D. A retórica em Franco Moretti: seus desdobramentos. Matraga: Estudos Linguísticos e Literários, Rio de Janeiro, v. 20, n. 33, p. 194-211, 2013.

FARO, J. S. À flor da pele: narrativas híbridas, cotidiano e comunicação. In: Apontamentos sobre jornalismo e cultura. Porto Alegre: Buqui, 2014.

FISCHER, L. A. Moretti busca fazer história mundial da literatura. Folha de S.Paulo, São Paulo, 27 set. 2009. Caderno Mais! Disponível em: <http:// bit.ly/2vbRTYM>. Acesso em: $1^{\circ}$ mar. 2016.

GALTUNG, J.; RUGE, M. H. The structure of foreign news: the presentation of the Congo, Cuba and Cyprus crises in four Norwegian newspapers. Journal of Peace Research, Thousand Oaks, v. 2, n. 1, p. 64-90, 1965. 
GANS, H. J. Deciding what's news: a study of CBS Evening News, NBC Nightly News, Newsweek and Time. Ed. ampl. comemorativa de $25^{\circ}$ aniversário. Evanston: Northwestern University Press, 2004.

GENRO FILHO, A. O segredo da pirâmide: para uma teoria marxista do jornalismo. Florianópolis: Insular, 2012. v. 6. (Série Jornalismo a Rigor).

HALL, S. Culture, the media and the ideological effect. In: CURRAN, J.; GUREVITCH, M.; WOOLLACOTT, J. (Orgs.). Mass communication and society. Londres: Edward Arnold; Open University Press, 1977. p. 315-348. (Série Set Books - Open University).

LUKÁCS, G. Soul \& form. Nova Iorque: Columbia University Press, 2010. (Série Columbia themes in philosophy, social criticism and the arts).

MARTÍN-BARBERO, J. O longo processo de enculturação. In: Dos meios às mediações: comunicação, cultura e hegemonia. Rio de Janeiro: UFRJ, 2003. p. 127-141.

MORETTI, F. Conjecturas sobre a literatura mundial. In: SADER, E. (Org.). Contracorrente: o melhor da New Left Review em 2000. Rio de Janeiro: Record, 2001. p. 45-64.

. O século sério. Revista Novos Estudos, São Paulo, n. 65, p. 3-33, mar. 2003. . A alma e a harpia. In: . Signos e estilos da modernidade: ensaios sobre a sociologia das formas literárias. Rio de Janeiro: Civilização Brasileira, 2007. p. 13-56.

. (Org.). A cultura do romance. São Paulo: Cosac Naify, 2009. v. 1. (Coleção O Romance).

. O burguês: entre a história e a literatura. São Paulo: Três Estrelas, 2014.

PONTE PRETA, S. O melhor de Stanislaw Ponte Preta: crônicas escolhidas. 2. ed. Rio de Janeiro: José Olympio, 1979.

SCHWARCZ, L.; BOTELHO, A. Ao vencedor as batatas 30 anos: crítica da cultura e processo social - entrevista com Roberto Schwarz. Revista Brasileira de Ciências Sociais. v. 23, n. 67, p. 147-160, jun. 2008. DOI: http://dx.doi. org/10.1590/S0102-69092008000200011

SCHWARZ, R. As ideias fora do lugar. In: . Ao vencedor as batatas. São Paulo: Duas Cidades, 1977. p. 13-25.

. Martinha versus Lucrécia: ensaios e entrevistas. São Paulo: Companhia das Letras, 2012.

SCHUDSON, M. Discovering the news: a social history of American newspapers. Nova Iorque: Basic Books, 1978.

. The sociology of news. Nova Iorque; Londres: W.W. Norton \& Company, 2003. 
SODRÉ, M. A narração do fato: notas para uma teoria do acontecimento. Petrópolis: Vozes, 2009.

SOUSA, J. P. Tobias Peucer: progenitor da teoria do jornalismo. Revista Estudos em Jornalismo e Mídia, Florianópolis, v. 1, n. 2, p. 31-47, jul./dez. 2004.

TALESE, G. O reino e o poder: uma história do New York Times. São Paulo: Companhia das Letras, 2000.

TRAQUINA, N. Teorias do jornalismo: a tribo jornalística - uma comunidade interpretativa internacional. 2. ed. Florianópolis: Insular, 2008. v. 2.

WARK, M. The engine room of Literature: on Franco Moretti. Los Angeles Review of Books, Los Angeles, 5 jun. 2013. Disponível em <http://bit.ly/2vl0GHq >. Acesso em: $1^{\circ}$ fev. 2016.

WERNECK, H. A arte de sujar os sapatos. In: TALESE, G. Fama e anonimato. São Paulo: Companhia das Letras, 2004. p. 523-535.

WOLF, M. Teorias da comunicação. 8. ed. Lisboa: Presença, 2003.

Artigo recebido em 26 de abril de 2016 e aprovado em 25 de julho de 2017. 